Vietnam Journal of Mechanics, NCST of Vietnam Vol. 23, 2001, No 4 (224-233)

\title{
STATIC DIAGNOSIS OF MULTIPLE CRACKED BEAM
}

\author{
TRAN VAN LIEN \\ University of Civil Engineering \\ NGUYen TIEN KHIEM \\ Institute of Mechanics, NCST of Vietnam
}

\section{Model of multiple cracked beam}

Model of crack was studied by many authors. Adams R. D. and Cawley P. in 1978 have proposed an axial spring model [1] to investigate the problem of location of crack in a bar using natural frequencies and mode shape. However, in [1] the stiffness of the equivalent spring has not been calculated from the crack depth. The formula relating the spring stiffness and crack depth has been established due to study of Ju and others [2] in 1982. Subsequent studies by Haisty B. S. and Springer W. T. [3] and Dimaroganas A. D. and Chondros T. G. [4] have made a great progress in improvement of the formula. In this paper the rotational spring model of transverse crack in beam developed in studies of Dimaroganas A. D. and his coworkers is adopted and used for solving the crack detection problem. The beam with single transverse crack has been studied in a lot of publications [5, 6]. Less amount of works $[7,8]$ devoted to the case of multiple cracked beam, especially to the problem of multi crack detection. Following our study in [8] concerned the multiple cracked beam, the problem of multi crack detection using static displacements measured in a beam is considered in the present paper. The theoretical investigation will be illustrated by a numerical example for a cantilever beam with two and three cracks.

Thus, a crack of the depth $a$ at the position $x^{*}$ (Figure 1.a), following to the [4] may be modeled as a rotational spring of stiffness

$$
K=\frac{1}{\alpha} ; \quad \alpha=\frac{6 \pi\left(1-\nu^{2}\right) h}{E I_{z}} I_{c}\left(\frac{a}{h}\right),
$$

where

$$
\begin{aligned}
I_{c}(z)= & 0.6272 z^{2}-1.04533 z^{3}+4.5948 z^{4}-9.973 z^{5}+20.2948 z^{6}-33.0351 z^{7} \\
& +47.1063 z^{8}-40.7556 z^{9}+19.6 z^{10}
\end{aligned}
$$

which is determined experimentally. Therefore, a beam with $n$ cracks of depth $a_{j}$ at $x_{j}, j=1, \ldots, n$ can be modeled as shown in Figure 1.b. 


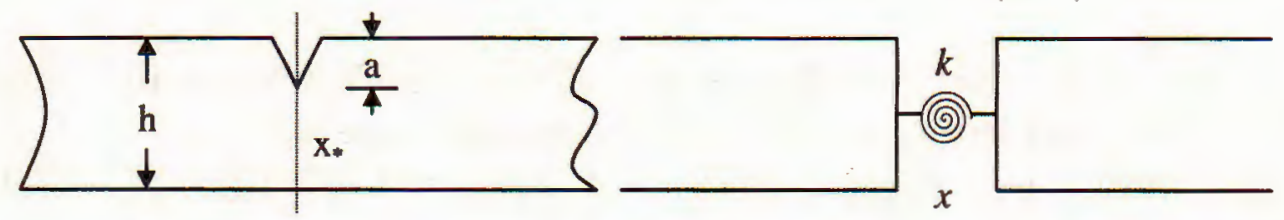

a)

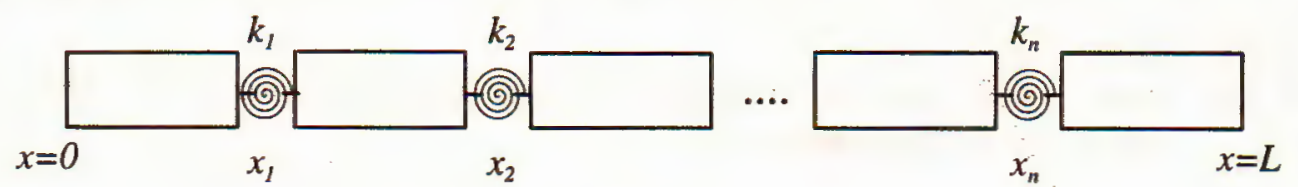

b)

Fig. 1

2. Static response of multiple cracked beam

Let us consider the beam in bending only, described by the equation:

$$
E I_{z} \frac{d^{4} \Phi(x)}{d x^{4}}=q(x)
$$

where $\Phi(x)$ is the flexural displacement of the beam at section $x$ and $q(x)$ is a distributed load Introduce the notations

$$
U_{1}=\Phi(0) ; \quad U_{2}=\Phi^{\prime}(0) ; \quad U_{3}=\Phi(L) ; \quad U_{4}=\Phi^{\prime}(L) .
$$

which is the generalized displacement of the beam and represents vector of degree of freedom $U=\left\{U_{1}, U_{2}, U_{3}, U_{4}\right\}^{T}$ and

$$
P_{1}=E I_{z} \Phi^{\prime \prime \prime}(0) ; \quad P_{2}=-E I_{z} \Phi^{\prime \prime}(0) ; \quad P_{3}=-E I_{z} \Phi^{\prime \prime \prime}(L) ; \quad P_{4}=E I_{z} \Phi^{\prime \prime}(L)
$$

being a vector of the end forces. These displacements and forces are shown in Figure 2.

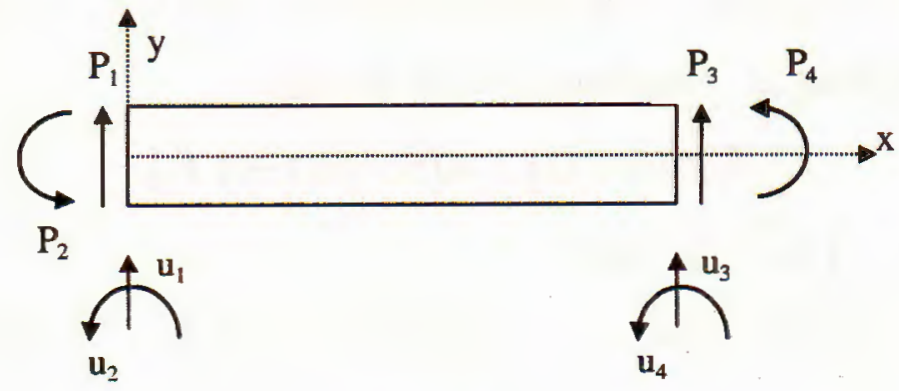

Fig. 2

For displacements and forces at the section $x_{j}, j=1, \ldots, n$ one uses the notations

$$
\begin{aligned}
& \left\{Z^{-}(j)\right\}=\left\{Z_{1}^{-}(j), Z_{2}^{-}(j), Z_{3}^{-}(j), Z_{4}^{-}(j)\right\} \\
& \left\{Z^{+}(j)\right\}=\left\{Z_{1}^{+}(j), Z_{2}^{+}(j), Z_{3}^{+}(j), Z_{4}^{+}(j)\right\} ; \quad j=1,2, \ldots, n
\end{aligned}
$$


$Z_{1}^{ \pm}(j)=\Phi\left(x_{j} \pm 0\right) ; \quad Z_{2}^{ \pm}(j)=\Phi^{\prime}\left(x_{j} \pm 0\right) ; \quad Z_{3}^{ \pm}(j)= \pm E I_{z} \Phi^{\prime \prime \prime}\left(x_{j} \pm 0\right) ; \quad z_{4}^{ \pm}(j)=$ $\mp E I_{z} \Phi^{\prime \prime}\left(x_{j} \pm 0\right)$, and letting $x_{0}=0, x_{n+1}=L$ one will have also

$Z_{1}^{+}(0)=\Phi(0)=U_{1} ; \quad Z_{2}^{+}(0)=\Phi^{\prime}(0)=U_{2} ; \quad Z_{3}^{+}(0)=E I_{2} \Phi^{\prime \prime \prime}(0)=P_{1} ; \quad Z_{4}^{+}(0)=$ $-E I_{2} \Phi^{\prime \prime}(0)=P_{2}$

$Z_{1}^{-}(n+1)=\Phi(L)=U_{3} ; Z_{2}^{-}(n+1)=\Phi^{\prime}(L)=U_{4} ; Z_{3}^{-}(n+1)=-E I_{z} \Phi^{\prime \prime \prime}(L)=$ $P_{3} ; Z_{4}^{-}(n+1)=E I_{z} \phi^{\prime \prime}(L)=P_{4}$.

On the other hand, general solution of equation (2.1) for $x \in\left(x_{j-1}, x_{j}\right)$, $j=1,2, \ldots, n+1$ can be represented as

$$
\Phi(x)=\Phi_{0}(\bar{x})+\frac{1}{6 E I_{z}} \int_{0}^{\bar{x}}(\bar{x}-\tau)^{3} q\left(x_{j-1}+\tau\right) d \tau ; \quad x \in\left[x_{j-1}, x_{j}\right] ; \quad \bar{x}=x-x_{j-1}
$$

where

$\Phi_{0}(x)=Z_{1}^{+}(j-1)+\bar{x} Z_{2}^{+}(j-1)+\frac{\bar{x}^{3}}{6 E I_{z}} Z_{3}^{+}(j-1)-\frac{\bar{x}^{2}}{2 E I_{z}} Z_{4}^{+}(j-1), \bar{x}=x-x_{j-1}$.

Furthermore, introducing the functions

$$
\begin{array}{ll}
\bar{q}_{1}\left(\ell_{j}\right)=\frac{1}{6 E I_{z}} \int_{0}^{\ell_{j}}\left(\ell_{j}-\tau\right)^{3} q\left(x_{j-1}+\tau\right) d \tau, & \bar{q}_{3}\left(\ell_{j}\right)=-\int_{0}^{\ell_{j}} q\left(x_{j-1}+\tau\right) d \tau, \\
\bar{q}_{2}\left(\ell_{j}\right)=\frac{1}{2 E I_{z}} \int_{0}^{\ell_{j}}\left(\ell_{j}-\tau\right)^{2} q\left(x_{j-1}+\tau\right) d \tau, & \bar{q}_{4}\left(\ell_{j}\right)=\int_{0}^{\ell_{j}}\left(\ell_{j}-\tau\right) q\left(x_{j-1}+\tau\right) d \tau
\end{array}
$$

one will have a vector of generalized load

$$
\{\bar{q}(j)\}=\left\{\bar{q}_{1}\left(\ell_{j}\right), \bar{q}_{2}\left(\ell_{j}\right), \bar{q}_{3}\left(\ell_{j}\right), \bar{q}_{4}\left(\ell_{j}\right)\right\} ; \quad j=1,2, \ldots, n+1 .
$$

Following the method of transfer matrix [8] one gets

$$
\left\{Z^{-}(n+1)\right\}=\mathbf{Q}\left\{Z^{+}(0)\right\}+\{\tilde{F}\}
$$

where the matrix $\mathbf{Q}$ is of the form

$$
\mathrm{Q}=T_{n+1} Q(n) Q(n-1) \ldots Q(1)=T_{n+1} J_{n} T_{n} J_{n-1} \ldots J_{2} T_{2} J_{1} T_{1}
$$

with $Q(j)=J_{j} T_{j}$ and

$$
T_{j}\left(\ell_{j}\right)=\left(\begin{array}{cccc}
1 & \ell_{j} & \ell_{j}^{3} / 6 E I_{z} & -\ell_{j}^{2} / 2 E I_{z} \\
0 & 1 & \ell_{j}^{2} / 2 E I_{z} & -\ell_{j} / E I_{z} \\
0 & 0 & -1 & 0 \\
0 & 0 & \ell_{j} & -1
\end{array}\right) ; \quad \ell_{j}=x_{j}-x_{j-1} ; j=1, \ldots, n+1,
$$




$$
J_{j}=J\left(\alpha_{j}\right)=\left(\begin{array}{cccc}
1 & 0 & 0 & 0 \\
0 & 1 & 0 & \alpha_{j} \\
0 & 0 & -1 & 0 \\
0 & 0 & 0 & -1
\end{array}\right) ; \quad j=1, \ldots, n ; \quad \alpha_{j}=\frac{6 \pi\left(1-\nu^{2}\right) h}{E I_{z}} I_{c}\left(\frac{a_{j}}{h}\right)
$$

The vector $\{\tilde{F}\}$ is calculated by the formula:

$$
\begin{aligned}
\{\tilde{F}\}= & \bar{q}(n+1)+T_{n+1} J_{n} \bar{q}(n)+T_{n+1} J_{n} T_{n} J_{n-1} \bar{q}(n-1)+ \\
& +T_{n+1} J_{n} T_{n} J_{n-1} T_{n-1} J_{n-2} \bar{q}(n-2)+\cdots+T_{n+1} J_{n} T_{n} \ldots J_{2} T_{2} J_{1} \bar{q}(1) .
\end{aligned}
$$

Writing the matrix $[Q]$ into the form $\mathbf{Q}=\left(\begin{array}{ll}\mathbf{Q}_{1} & \mathbf{Q}_{2} \\ \mathbf{Q}_{3} & \mathbf{Q}_{4}\end{array}\right)$, where

$$
\mathrm{Q}_{1}=\left(\begin{array}{ll}
Q_{11} & Q_{12} \\
Q_{21} & Q_{22}
\end{array}\right) ; \quad \mathbf{Q}_{2}=\left(\begin{array}{ll}
Q_{13} & Q_{14} \\
Q_{23} & Q_{24}
\end{array}\right) ; \quad \mathbf{Q}_{3}=\left(\begin{array}{ll}
Q_{31} & Q_{32} \\
Q_{41} & Q_{42}
\end{array}\right) ; \quad \mathbf{Q}_{4}=\left(\begin{array}{ll}
Q_{33} & Q_{34} \\
Q_{43} & Q_{44}
\end{array}\right)
$$

and using the notations introduced above, we have from (2.5)

$$
\left(\begin{array}{l}
U_{3} \\
U_{4}
\end{array}\right)=\mathbf{Q}_{1}\left(\begin{array}{l}
U_{1} \\
U_{2}
\end{array}\right)+\mathbf{Q}_{2}\left(\begin{array}{l}
P_{1} \\
P_{2}
\end{array}\right)+\left(\begin{array}{l}
\tilde{F}_{1} \\
\tilde{F}_{2}
\end{array}\right) ; \quad\left(\begin{array}{l}
P_{3} \\
P_{4}
\end{array}\right)=\mathbf{Q}_{3}\left(\begin{array}{l}
U_{1} \\
U_{2}
\end{array}\right)+\mathbf{Q}_{4}\left(\begin{array}{l}
P_{1} \\
P_{2}
\end{array}\right)+\left(\begin{array}{l}
\tilde{F}_{3} \\
\tilde{F}_{4}
\end{array}\right)
$$

that can be written in the matrix form,

$$
\mathbf{K}\{U\}=\{P\}+\mathbf{G}\{\tilde{F}\},
$$

where

$$
\mathbf{K}=\left(\begin{array}{cc}
-\mathbf{Q}_{2}^{-1} \mathbf{Q}_{1} & \mathbf{Q}_{2}^{-1} \\
\mathbf{Q}_{3}-\mathbf{Q}_{4} \mathbf{Q}_{2}{ }^{-1} \mathbf{Q}_{1} & \mathbf{Q}_{4} \mathbf{Q}_{2}^{-1}
\end{array}\right) ; \quad \mathbf{G}=\left(\begin{array}{cc}
\mathbf{Q}_{2}^{-1} & 0 \\
\mathbf{Q}_{4} \mathbf{Q}_{2}^{-1} & -I
\end{array}\right)
$$

$\mathbf{K}$ is the stiffness matrix and $\{F\}=\mathbf{G}\{\tilde{F}\}$ is vector of generalized load. Suppose furthermore that the boundary conditions are linear of the form

$$
\mathbf{B}_{u}\{U\}+\mathbf{B}_{p}\{P\}=0
$$

where

$$
\mathbf{B}_{u}=\left(\begin{array}{cccc}
B_{11}^{0} & B_{12}^{0} & 0 & 0 \\
B_{21}^{0} & B_{22}^{0} & 0 & 0 \\
0 & 0 & B_{11}^{L} & B_{12}^{L} \\
0 & 0 & B_{21}^{L} & B_{22}^{L}
\end{array}\right) ; \quad \mathbf{B}_{p}=\left(\begin{array}{cccc}
B_{13}^{0} & B_{14}^{0} & 0 & 0 \\
B_{23}^{0} & B_{24}^{0} & 0 & 0 \\
0 & 0 & B_{13}^{L} & B_{14}^{L} \\
0 & 0 & B_{23}^{L} & B_{24}^{L}
\end{array}\right)
$$

then $(2.10)$ can be rewritten as

$$
\mathbf{K}_{u}\{U\}+\mathbf{K}_{p}\{P\}=-\{\tilde{F}\}
$$


with

$$
\mathbf{K}_{u}=\left(\begin{array}{cc}
\mathbf{Q}_{1} & -I \\
\mathbf{Q}_{3} & 0
\end{array}\right) ; \quad \mathbf{K}_{p}=\left(\begin{array}{cc}
\mathbf{Q}_{2} & 0 \\
\mathbf{Q}_{4} & -I
\end{array}\right)
$$

Finally, equations (2.12) and (2.14) must be solved together, so they form a system

$$
\overline{\mathbf{K}}\{\bar{U}\}=-\{\bar{P}\},
$$

where

$$
\overline{\mathbf{K}}=\left(\begin{array}{ll}
\mathbf{K}_{u} & \mathbf{K}_{p} \\
\mathbf{B}_{u} & \mathbf{B}_{p}
\end{array}\right) ; \quad\{\bar{U}\}=\left(\begin{array}{l}
\{U\} \\
\{P\}
\end{array}\right) ; \quad\{\bar{P}\}=-\left(\begin{array}{l}
\{\tilde{F}\} \\
\{0\}
\end{array}\right)
$$

Solving equation (2.16) gives as vector of generalized displacements, as well as the vector of friction end forces or in fact the state vectors $\left\{Z^{+}(0)\right\},\left\{Z^{-}(n+1)\right\}$. Using the result obtained one can determine fully the field of displacement, slope, bending moment and shear force:

$$
\begin{gathered}
\left\{Z^{+}(j)\right\}=\mathbf{Q}(J)\left\{Z^{+}(j-1)\right\}+\mathrm{J}_{\mathrm{j}}\left\{\bar{q}\left(\ell_{j}\right)\right\}, \quad j=1, \ldots, n \\
\{Z(x)\}=\left[T_{j}(\lambda, \bar{x})\right]\left\{Z^{+}(j-1)\right\}+\{\bar{q}(\bar{x})\} . \quad \bar{x}-x_{j-1} .
\end{gathered}
$$

Here

$$
\{Z(x)\}=\left\{Z_{1}(x), Z_{2}(x), Z_{3}(x), Z_{4}(x)\right\}^{T}=\left\{\Phi(x), \Phi^{\prime}(x),-E I_{z} \Phi^{\prime \prime \prime}(x), E I_{z} \Phi^{\prime \prime}(x)\right\}^{T}
$$

Let's consider a cantilever beam loaded by a force $F$ applied to the free end. In the case of uncracked beam one has

$$
\Phi_{0}^{F}(x)=-\frac{F x^{3}}{6 E I_{z}}+\frac{F L x^{2}}{2 E I_{z}} ; \quad U_{3}=\Phi_{0}^{F}(L)=-\frac{F L^{3}}{3 E I_{z}} ; \quad \Phi_{0}^{\prime F}(L)=-\frac{F L^{2}}{2 E I_{z}} .
$$

For cantilever beam with cracks at positions $\left\{x_{j} ; j=1,2, \ldots, n\right\}$ and with depth $\left\{a_{j} ; j=1,2, \ldots, n\right\}$, the given load $F$ leads to the field of displacement

$$
\Phi(x)=\left\{\begin{array}{lc}
\Phi_{0}(x)=\Phi_{0}^{F}(x)=-\frac{F x^{3}}{6 E I_{z}}+\frac{F L x^{2}}{2 E I_{z}} & \text { for } 0 \leq x \leq x_{1} \\
\Phi_{1}(c)=\Phi_{0}^{F}(x)-F \alpha_{1}\left(x-x_{1}\right)\left(L-x_{1}\right) & \text { for } x_{1} \leq x \leq x_{2} \\
\cdots \quad \cdots \quad \cdots & \cdots \\
\Phi_{n}(x)=\Phi_{0}^{F}(x)-\sum_{j=1}^{n} F \alpha_{j}\left(x-x_{j}\right)\left(L-x_{j}\right) & \text { for } x_{n} \leq x \leq L .
\end{array}\right.
$$

In particular, at free end $x=L$ the displacement and slope are 


$$
\begin{aligned}
& U_{3}=\Phi_{0}^{F}(L)=-\frac{F L^{3}}{3 E I_{z}}\left[1+\frac{3 E I_{z}}{L^{3}} \sum_{j=1}^{n} \alpha_{j}\left(L-x_{j}\right)^{2}\right] \\
& U_{4}=\Phi_{0}^{\prime F}(L)=-\frac{F L^{2}}{2 E I_{z}}\left[1+\frac{2 E I_{z}}{L^{3}} \sum_{j=1}^{n} \alpha_{j}\left(L-x_{j}\right)\right] .
\end{aligned}
$$

Comparing (2.22) and (2.20), one can obtain the factors representing amplification due to cracks of displacement and slope as follow

$$
A_{3}^{F}=\left[1+\frac{3 E I_{z}}{L^{3}} \sum_{j=1}^{n} \alpha_{j}\left(L-x_{j}\right)^{2}\right] ; \quad A_{4}^{F}=\left[1+\frac{2 E I_{z}}{L^{3}} \sum_{j=1}^{n} \alpha_{j}\left(L-x_{j}\right)\right]
$$

Analogously, in the case of uniformly distributed load $q$, the displacement field can be found in the form

$$
\Phi(x)=\left\{\begin{aligned}
\Phi_{0}(x)= & \Phi_{0}^{q}(x)=-\frac{q x^{4}}{24 E I_{z}}+\frac{q L x^{3}}{6 E I_{z}}-\frac{q L^{2} x^{2}}{4 E I_{z}} \quad \text { for } 0 \leq x \leq x_{1} \\
\Phi_{1}(x)= & \Phi_{0}^{q}(x)-\frac{q \alpha_{1}}{2}\left(x-x_{1}\right)\left(L-x_{1}\right)^{2} \quad \text { for } x_{1} \leq x \leq x_{2} \\
\Phi_{2}(x)= & \Phi_{0}^{q}(x)-\frac{q \alpha_{1}}{2}\left(x-x_{1}\right)\left(L-x_{1}\right)^{2} \\
& -\frac{q \alpha_{2}}{2}\left(x-x_{2}\right)\left(L-x_{2}\right)^{2} \quad \text { for } x_{2} \leq x \leq x_{3} \\
& \cdots \quad \cdots \\
\cdots & \cdots \\
\Phi_{n}(x)= & \Phi_{0}^{q}(x)-\sum_{j=1}^{n} \frac{q \alpha_{j}}{2}\left(x-x_{j}\right)\left(L-x_{j}\right)^{2} \quad \text { for } x_{n} \leq x \leq L .
\end{aligned}\right.
$$

In this case the amplification factors for displacement and slope at the free end have the analogous to the (2.23) form

$$
A_{3}^{q}=\left[1+\frac{4 E I_{z}}{L^{4}} \sum_{j=1}^{n} \alpha_{j}\left(L-x_{j}\right)^{3}\right] ; \quad A_{4}^{q}=\left[1+\frac{3 E I_{z}}{L^{3}} \sum_{j=1}^{n} \alpha_{j}\left(L-x_{j}\right)^{2}\right] .
$$

\section{Crack detection by using static displacement}

In this section the problem of crack detection for a cantilever beam by displacement measured at various positions under static load applied to the free end is studied. To identify the crack parameters $\left\{\lambda_{j}\right\}=\left\{a_{j}, x_{j}\right\}, j=1, \ldots, n$ it is necessary to measure displacements at $2 n$ points. Moreover, the function-displacement as shown in (2.21) can be calculated at a point if amount of the cracks on the left

of the point is known. This fact constrains one to assume that measurement points 
must be distributed as shown in Figure 3. It means that the measurement points are coupled $\left(u_{j}, u_{j+1}\right), j=1, \ldots, n$, no crack exists between the points in the pair and in the interval between the pairs there is only single crack. In practice the assumption is not much strict, because one can choose the measurement points mesh freely.

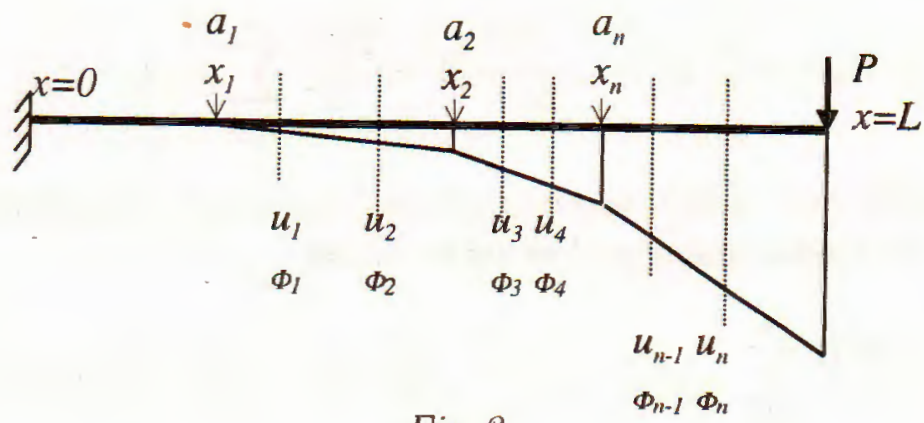

Fig. 3

Thus, it is supposed that the static displacements measured at the chosen mesh $\left(u_{1}, u_{2}, \ldots, u_{2 n-1}, u_{2 n}\right)$ are $\left(\Phi_{1}, \Phi_{2}, \ldots, \Phi_{2 n-1}, \Phi_{2 n}\right)$. We Introduce the function of crack parameters $\lambda=\left\{a_{1}, x_{1}, a_{2}, x_{2}, \ldots, a_{n}, x_{n}\right\}$ :

$$
\begin{aligned}
f(\lambda)= & f\left(a_{1}, x_{1}, a_{2}, x_{2}, \ldots, a_{n}, x_{n}\right)= \\
= & \left|\Phi_{1}+F \alpha_{1}\left(u_{1}-x_{1}\right)\left(L-x_{1}\right)\right|^{2}+\left|\bar{\Phi}_{2}+F \alpha_{1}\left(u_{2}-x_{1}\right)\left(L-x_{1}\right)\right|^{2}+\cdots+ \\
& +\left|\bar{\Phi}_{2 n-1}+\sum_{j=1}^{n} F \alpha_{j}\left(u_{2 n-1}-x_{j}\right)\left(L-x_{j}\right)\right|^{2} \\
& +\left|\bar{\Phi}_{2 n}+\sum_{j=1}^{n} F \alpha_{j}\left(u_{2 n}-x_{j}\right)\left(L-x_{j}\right)\right|^{2} \\
& \bar{\Phi}_{k}=\Phi_{k}-\Phi_{0}^{F}\left(u_{k}\right), \quad k=1,2, \ldots, 2 n .
\end{aligned}
$$

The arguments of the function (3.1) are constrained by

$$
\begin{aligned}
0 \leq x_{1} \leq u_{1}<u_{2} & \leq x_{2} \leq u_{3} \leq u \cdots x_{n} \leq u_{2 n-1}<u_{2 n} \leq L \\
0 & \leq a_{j}<h ; \quad j=1,2, \ldots, n
\end{aligned}
$$

where

$$
\begin{aligned}
\alpha_{j}= & \frac{6 \pi\left(1-\nu^{2}\right) h}{E I_{z}} I_{c}\left(\frac{a_{j}}{h}\right), \quad j=1,2, \ldots, n ; \\
I_{c}(z)= & 0.6272 z^{2}-1.04533 z^{3}+4.5948 z^{4}-9.973 z^{5}+20.2948 z^{6}-33.0351 z^{7} \\
& +47.1063 z^{8}-40.7556 z^{9}+19.6 z^{10} .
\end{aligned}
$$

The diagnosis problem now can be formulated as a nonlinear programming problem 


$$
\left\{\begin{array}{l}
f(\lambda) \rightarrow \min \\
G_{j}(\lambda)=0 ; \quad j=1,2, \ldots, m_{e} \\
G_{j}(\lambda) \leq 0 ; \quad j=m_{e}+1, \ldots, m \\
\lambda_{\ell b} \leq \lambda \leq \lambda_{u b}
\end{array}\right.
$$

For solving the problem (3.3), algorithms given in MATLAB [10] can be used and in result one obtains crack position $x_{j}$ and crack depth $a_{j}$. Input for the algorithm is static displacements measured at various points along the beam.

\section{Numerical example and discussion}

To illustrate the procedure proposed for crack detection, a cantilever beam with following properties is studied.

The length $L=3 \mathrm{~m}$, cross section area $A=0.2 \mathrm{~m} \times 0.2 \mathrm{~m}$, Young's Modulus $E=2.1 \cdot 10^{11} \mathrm{~N} / \mathrm{m}^{2}$, the force applied to free end $P=3 \mathrm{kN}$.

Let's consider four scenarios of cracked beam as follow, the first scenario (S1) is the case of two cracks (at positions $1 \mathrm{~m}$ and $2 \mathrm{~m}$ from the fixed end of beam with depth of $0.06 \mathrm{~m}$ and $0.04 \mathrm{~m}$ respectively) and in the diagnosis problem only two cracks are sought. In this case the influence of the measurement noise on the diagnosis result is studied. The subsequence three cases under consideration are shown in Table 1.

Table 1

\begin{tabular}{|c|c|c|c|c|c|c|c|c|c|}
\hline \multirow{2}{*}{ Scenario } & \multicolumn{3}{|c|}{$S_{2}$ (two cracks) } & \multicolumn{3}{|c|}{$S_{3}$ (three cracks) } & \multicolumn{3}{|c|}{$S_{4}$ (three cracks) } \\
\hline & $1^{s t} \mathrm{cr}$ & $2^{\text {nd }} \mathrm{cr}$ & $\overline{3^{r d} \mathrm{cr}}$ & $1^{s t} \mathrm{cr}$ & $2^{\text {nd }} \mathrm{cr}$ & $3^{\text {rd }} \mathrm{cr}$ & $1^{s t} \mathrm{cr}$ & $2^{\text {nd }} \mathrm{cr}$ & $\overline{3^{r d} \mathrm{cr}}$ \\
\hline $\begin{array}{c}\text { Crack } \\
\text { Position }\end{array}$ & $1 \mathrm{~m}$ & $1.5 \mathrm{~m}$ & $2.0 \mathrm{~m}$ & $1 \mathrm{~m}$ & $1.5 \mathrm{~m}$ & $2.0 \mathrm{~m}$ & $1.0 \mathrm{~m}$ & $1.5 \mathrm{~m}$ & $2.0 \mathrm{~m}$ \\
\hline $\begin{array}{l}\text { Crack } \\
\text { depth }\end{array}$ & $0.0 \mathrm{~m}$ & $0.04 \mathrm{~m}$ & $0.06 \mathrm{~m}$ & $0.02 \mathrm{~m}$ & $0.04 \mathrm{~m}$ & $0.06 \mathrm{~m}$ & $0.02 \mathrm{~m}$ & $0.04 \mathrm{~m}$ & $0.06 \mathrm{~m}$ \\
\hline
\end{tabular}

In the case of scenario $S_{1}$ the measurement points mesh is $u_{1}=1.5 \mathrm{~m}, u_{2}=1.8 \mathrm{~m}$, $u_{3}=2.1 \mathrm{~m}, u_{4}=2.4 \mathrm{~m}, u_{5}=2.6 \mathrm{~m}, u_{6}=2.8 \mathrm{~m}$. For the scenarios $S_{2}, S_{3}$ the measurements are made at the positions $u_{1}=1.2 \mathrm{~m}, u_{2}=1.4 \mathrm{~m}, u_{3}=1.6 \mathrm{~m}$, $u_{4}=1.8 \mathrm{~m}, u_{5}=2.2 \mathrm{~m}, u_{6}=2.6 \mathrm{~m}$ and for the last case, $u_{1}=1.2 \mathrm{~m}, u_{2}=1.4 \mathrm{~m}$, $u_{3}=1.5 \mathrm{~m}, u_{4}=1.8 \mathrm{~m}, u_{5}=2.2 \mathrm{~m}, u_{6}=2.6 \mathrm{~m}$. It is necessary to note here that, in the second case $\left(S_{2}\right.$ in table 1$)$ only two cracks are presented, but in the diagnosis problem three cracks are sought. Of course, among the cracks one must be of zero depth. This case is considered to test the detection of zero depth crack. The last 
scenario $\left(S_{4}\right)$ is carried out for testing the case when measurement point is identical to the crack position.

The result of crack detection for the case of first scenario $S_{1}$ for different levels of measurement error, which has been introduced by addition of the term $\varepsilon$.rand, to the input of the crack detection program is given in Table 2. Here, $\varepsilon=0.0$; $0.01 ; \ldots ; 0.1$ corresponding to the $0 \%, 1 \%, 2 \%, \ldots, 10 \%$ of measurement error and rand is a random number uniformly distributed in the interval $(0,1)$. The cracks parameters detected in the three last scenarios are shown in Table 3.

\begin{tabular}{ccccccccccc}
\hline$\varepsilon$ & $\frac{0 \%}{\varepsilon}$ & $\frac{1 \%}{x_{1}}$ & 0.9998 & 0.9747 & 0.9540 & 0.9363 & 0.9216 & 0.9089 & 0.8979 & 0.8652 \\
$a_{1}$ & 0.0600 & 0.0625 & 0.0649 & 0.0671 & 0.0692 & 0.0713 & 0.0732 & 0.0800 \\
$x_{2}$ & 1.9995 & 1.9979 & 1.9969 & 1.9941 & 1.9937 & 1.9921 & 1.9907 & 1.9875 \\
$a_{2}$ & 0.0400 & 0.0420 & 0.0439 & 0.0457 & 0.0474 & 0.0490 & 0.0505 & 0.0562 \\
actual crack parameters: & $x_{1}$ & $=1.0$, & $a_{1}=0.06$, & $x_{2}$ & 2.0, & $a_{2}=0.04$ \\
\hline
\end{tabular}

\section{Conclusion}

In this paper the following results are presented:

1. General solution for static displacement of multiple cracked beam subjected to concentrated as well as distributed load is obtained in an analytical form.

2. The problem for crack detection of multiple cracked cantilever by measurements of static displacement has been formulated in a form of the constrained nonlinear programming, that may be solved by using MATLAB code.

3. An example has been investigated numerically to validate the developed herein theory. Different scenarios of cracks have been arranged and in each case the crack detection was tried. Results of detection given in Table 2, 3 show acceptability of the procedure proposed.

This work has been completed under support of the National Council in Natural Science of Vietnam.

\section{REFERENCES}

1. Adams R. D., Cawley P., Pie C. J. and Stone B. J. A. A vibration technique for 
non-destructively assessing the integrity of structures. Journal of Mechanical Engineering Science 20 (1978), 93-100.

2. Ju F.D., Akgun M., et al. "Diagnosis of Fracture Damage in Simple Structures", Report CE-62(82) AFOSR-993-1, Bureau of Engineering research, University of New Mexico 1982

3. Haisty B. S., Springer W. T. A general beam element for use in damage assessment of complex structures. Journal of Vibration, Acoustics, Stress and Reliability in Design 110 (1988), 389-394.

4. Chondros T. G., Dimarogonas A. D. and Yao J. A continuos cracked beam vibration theory. Journal of Sound and Vibration 215(1) (1998), 17-34.

5. Ostachowicz W. M. and Krawczuk M. Vibration analysis of a cracked beam. Computers \& Structures 36(2) (1990), 245-250.

6. Liang R. Y., Hu J. and Choy F. Theoretical study of crack-induced eigen-frequency changes on beam structures. Journal of Engineering Mechanics, ASCE, 118(2) (1992), 384-396.

7. Shrifin E. I. and Ruotolo R. Natural frequencies of a beam with an arbitrary number of cracks. Journal of Sound and Vibration 222(3) (1999), 409-423.

8. N. T. Khiem, T.V. Lien. A simplified method for natural frequency analysis of multiple cracked beam. Journal of Sound and Vibration 245(4) (2001), 737-751.

9. Nguyen Cao Menh, Nguyen Tien Khiem, Dao Nhu Mai, Nguyen Viet Khoa Modal analysis of damaged structures by the modified finite element method. Journal of Mechanics, NSNST of Vietnam, 19(1) (1998), 29-46.

10. Colleman T., Branch M. A., Grace A. Optimization toolbox for use with MATLAB. User's Guide Ver 2.0 The MATWORKS Inc. 1999

Received October 9, 2001

\section{CHẨN ĐOÁN TĨNH DẦ CÓ NHIỀU VẾT NỨT}

Trong bài báo này các tác giả trình bày một thuật toán chẩn đoán nhiều vết nứt trong dầm bằng phương pháp đo độ võng tĩnh. Việc chẩn đoán này dựa trên cơ sở kết quả nghiên cứu phản ứng của dầm có nhiều vết nứt đối với tải trọng ngoài, mà trong trường hợp tải trọng tĩnh cho kết quả giải tích. Thuật toán này được minh họa bằng một ví dụ số, trong đó xem xét thử nghiệm nhiều phương án vết nứt khác nhau. Đã nghiên cứu ảnh hưởng của sai số đo đạc đến kết quả chẩn đoán. Xét trường hợp chẩn đoán vết nứt $\delta$ độ sâu bằng không (nghĩa là không có nứt) và thử nghiệm trường hợp điểm đo trùng với vị trí vết nứt. Các kết quả cho thấy thuật toán này có độ chính xác và tính ổn định chấp nhận được. 